\title{
The impact of accounting information systems reliability on enhancing the requirements of planning process at Jordanian commercial banks
}

\author{
Mustafa S. Alathamneh ${ }^{a^{*}}$
}

a Jadara University, Jordan

\section{H R O N I C L E}

\section{Article history:}

Received: June 152019

Received in revised format: No-

vember 22019

Accepted: November 3, 2019

Available online:

November 5, 2019

Keywords:

Accounting information systems

(AIS)

Jordanian commercial banks

planning process requirements

Reliability

\begin{abstract}
A B S T R A C T
The study aimed to identify the impact of Accounting Information Systems (AIS) reliability on enhancing the requirements of planning process at Jordanian Commercial Banks, and in order to achieve the objectives of the study the researcher implemented the descriptive analytical approach by reviewing the literature related to AIS and planning process requirements. Researcher also designed a questionnaire to target the executive managers, financial managers, and departments' heads at the (13) Jordanian commercial banks, where (145) questionnaires were distributed, recovered (122), and (118) of those were found to be valid for analysis. The study used the SPSS and the Multiple Regression test to reach the objectives of the study and test its hypotheses. The results indicate a major impact of AIS reliability on fostering the planning process requirements at the Jordanian commercial banks, and recommended the need of managements to focus on AIS to assist for the development of plans and policies related to the various activities, which may be practiced by management.
\end{abstract}

(C) 2020 by the authors; licensee Growing Science, Canada

\section{Introduction}

The first years of $21^{\text {st }}$ century, witnessed enormous shifts and changes in the economic, political, and social systems, and this development has reflected on the nature of individuals, institutions, organizations, and countries. Commercial banks have become one of the main pillars that get affected by the transformations of economic environment represented in the hard competition within the market forces, free trade, communications and information technology advancement. Due to these dramatic developments in the economic environment and the things that accompany it from improvement in the accounting measurement methods, and operating the financial statements by using the computer systems, banks had to create and design a modern AIS with high reliability and capability to provide the quantities and types of useful information for the administrative decision makers with immediate, proper, secure, and integrated way for the strategical or operational proper planning. Accounting systems will response to these developments and interact with them, due to the fact that accounting system is one of the most important sources of obtaining quantitative and qualitative information, either in banks or companies. The accounting information provided by AIS in banks to perform its functions and achieve its objectives could not achieve the desired objective, unless it has high degree of security and reliability through an accurate and rational planning process, and this cannot happen except by providing a set of potentials and possibilities, such as the accurate forecasting, lack of prejudice, and reviewing the plans periodically, as well as periodic testing of assumptions' accuracy. This reflects on the entire planning function where the management plans are officially translated into so called planning budgets, which express the desires and objectives of management. Management needs the flow of integrated and good information which show the efficiency of plans implementation through comparing the actual performance data with the planning budgets' data to identify the problems and divergences. In fact, the success of any bank greatly depends on the reliability of produced information and the ability and efficiency of management to formulate the essential plans.

* Corresponding author. Tel.: +962799313686

E-mail address: mathamneh@jadara.edu.jo (M. S. Alathamneh) 


\section{Study Hypotheses}

There is no statistically significant impact of AIS reliability on enhancing the requirements of planning process at Jordanian Commercial Banks. It derives from it the following secondary hypotheses:

1. There is no statistically significant impact of AIS protection from unauthorized intrusions on enhancing the requirements of planning process at Jordanian Commercial Banks.

2. There is no statistically significant impact of AIS readiness activation standards on enhancing the requirements of planning process at Jordanian Commercial Banks.

3. There is no statistically significant impact of AIS integration and safety standards on enhancing the requirements of planning process at Jordanian Commercial Banks.

4. There is no statistically significant impact of AIS customers' privacy assurance on enhancing the requirements of planning process at Jordanian Commercial Banks.

5. There is no statistically significant impact of AIS confidential information protection on enhancing the requirements of planning process at Jordanian Commercial Banks.

The primary purpose of the study represented is to identify the impact that AIS reliability plays on enhancing the requirements of planning process at Jordanian Commercial Banks. It derives from the following secondary goals:

- Identify the impact of AIS protection from unauthorized intrusions on enhancing the requirements of planning process at Jordanian Commercial Banks.

- Identify the impact of AIS readiness activation standards on enhancing the requirements of planning process at Jordanian Commercial Banks.

- Identify the impact of AIS integration and safety standards on enhancing the requirements of planning process at Jordanian Commercial Banks.

- Identify the impact of AIS customers' privacy assurance on enhancing the requirements of planning process at Jordanian Commercial Banks.

- Identify the impact of AIS confidential information protection on enhancing the requirements of planning process at Jordanian Commercial Banks.

The importance of this study stems from the entrance of accounting information systems reliability in all areas of Bank work, and actively impact the customers and management decisions, through information which are provided for the banks' management as background material to assist them in the planning processes, and to emphasize its role in ensuring the quality, security, and reliability of accounting information produced used in promoting the planning processes' requirements.

\section{Theoretical Frameworks \& procedural Definitions}

This section deals with theoretical framework as well as procedural definitions.

\subsection{Accounting Information Systems Reliability}

Accounting information systems reliability plays a major and significant role and it is an essential source for management to strengthen its plans and control its processes, and it also plays a leading and a large role in the decision-making process (Phuong, 2017). As a result of the expansion processes, the geographical spreading, production diversity, intense competition, the human resources and finance needs and all other activities, most banks seek to develop a secure and reliable accounting system which align with the size of its financial operations, and guarantee the flow of these processes and information toward the development of management performance. AIS consists of a set of elements that help to achieve the goal created for, and according to Kanakriyah (2017) and Al-Rumhi and Al-Zeibah (2011), the most important elements of those are qualified people who are capable of operating the accounting information system, manual and computerize procedures and instructions used in data collection, processing and archiving the information related to banks' activities which foster the availability of data related to bank operations and its legal framework, select its activities aspects, and the infrastructure of information technology and the adopted electronic methods, in addition to the availability of internal control, and security measures and procedures that protect data. Al-Rumhi and Al-Zeibah (2011) define accounting information systems as systems that collect, record, store, and process the financial data to produce information for decision makers to help them make the appropriate decisions. Edmond Gel (2010) identifies it as a comprehensive framework for a set of human or physical components, which include the elements and procedures that work together in a coherent and integrated way by implementing the system functions that begin with entering the data, running the financial statements, retrieving the results, and finally delivering the information to the beneficiary groups to assist them in making the necessary decisions and perform their functions in a timely manner. Researcher sees accounting information systems as the part of bank's management information systems, which can be simple or complex and these systems collect the financial and non-financial data from internal and external sources, process it, and then transform it into meaningful information for the management of the bank. 


\subsection{Accounting Information System Security \& Reliability}

Protecting information from unauthorized intrusions consider the driving force and the needed fuel to operate the accounting systems securely, which can be obtained from multiple sources. Researcher believes that protecting information in the accounting systems is often expressed by complex codes and algorithms prepared specially for this purpose. In spite of the protection type, there must be another component of system reliability where accounting systems would be on high readiness at any time. In addition, the produced information must be sound, integrated, accurate, and comprehensive where customer privacy does not get affected by the bank and in the same time not to lose any protection of confidential information related to the customers. This can ensure that processes will be used to convert input or data into output or information that are valuable for either management or client, which result from secured accounting systems. However, as researcher previously mentioned it is necessary to have a control system in order to get feedback that could help management correct the distractions and shortcoming (Abu-Mahdi, 2017). It is possible to say that management needs good, safe, and secure accounting information systems to support it in performing a set of functions, where the most important of those are collecting and storing data related to institution operations efficiently and effectively, and processing data to turn it into a final product as information, and then delivering it to users through providing security, protection, and controlling of data and information produced (Almbaidin, 2014). It is worth mentioning here that AIS will be addressed in one of two forms, which are financial accounting information systems and management accounting information systems, where (Abu-Hasheish, 2005) mentioned that the difference between these systems is a difference in the time scope and also a difference in the ways and methods used to analyze the data and retrieve the required information. In order for accounting systems to be effective, safe, and appropriate for planning and decision-making processes it must have some features and potentials, like to be helpful for user, to be flexible where it can be adjusted or change as necessary, and to have the accuracy and coherence between its components, through real and strict set of rules which take into account the size of designed systems cost, taking into consideration these systems are providing the smoothness and safety at time of reviewing it and auditing it. In addition, the availability of supported assistance for information to have a clear effect, which foster and strengthen the characteristics of these systems in order for it to be at the highest degree of efficiency and effectiveness (Kanakriyah, 2017).

\subsection{Planning Process Requirements}

Planning generate awareness among corporate management and focus its attention into the future, which enables them to identify the problem areas and makes good decisions at the right time, where planning is defined as the activity that deals with determining the goals, objectives, future results of the company that it plans to achieve, and illustrates the activities, programs, and needed procedures to achieve these goals (Harem, 2009). Al-Dalahmeh (2008) and Almbaidin (2014) identify it as the way that has been drawn for authorities, in advance to guide them at the time of making decisions and implementing the work. Researcher sees that planning process is significantly linked to the accounting field, where the planning budgets consider one of the most important planning tools used by banks, where it rests on senior management to put the strategic goals of banks, then the middle management translates these goals into workable methods, and then lower management implements these plans and methods to reach the designed goals. From here, the planning process goes through five key phases (Kanakriyah, 2017; Tawfiq, 2010), where it starts with collecting data, fact, and information about the resources and circumstances surrounding the bank, identifying the possible targets, preparing the strategic plans which will be translated into secondary and timely plans, and finally identifying the periodic programs for future periods with stating the policies that will be implemented. Researcher sees that accounting information reliability provided by the accounting systems play a leading and significant role at every stage of the above stages, by providing the necessary data for preparing the planning budgets. But in order to achieve that, a set of requirements must be provided for the planning process to be effective and achieve its purpose (Kahaleh \& Hanan, 2011).

\section{Previous Studies}

The study of Abu-Mahdi (2017) aimed to measure the principles of electronic accounting systems reliability and identify its impact on banking performance indicators, financial performance indicators analysis, operational performance, and performance of stocks and shares, and also identify the influence level of these principles on banking performance indicators of local banks operating in Palestine. To achieve these goals, a study was conducted on the domestic banks operating in Palestine and licensed by the Palestinian Money Authority (PMA), where it depended on two primary sources of information represented in the secondary sources which through it addressed and analyzed the theoretical framework of the study. The most important results of the study were the commitment of Palestinian banks listed in Palestine stock exchange to implement the principles of AIS reliability and provide the five principle requirements of AIS reliability established by the American Institute and the Canadian Institute of Chartered Accountants. The study recommendations included strengthening the interest and attention of Palestinian banking management to implement the principles of reliability, due to its significant impact on the annual business results, PMA will require the companies that get listed in the stock market to implement the principles of AIS reliability, and also to care about finding the appropriate alternatives and solutions to keep the Palestinian banking system ready to work under any circumstances, especially in the besieged Gaza Strip for its frequent wars. 
The study of Mushtaha et al. (2011) aimed to highlight the scientific underpinnings of AIS reliability principles to be one of the internal auditor tasks, measure the reliability of AIS in the Jordanian and Palestinian banks, discuss the expected impact of AIS reliability at the Jordanian and Palestinian banks on its performance indicators, and conduct a comparative study between the Jordanian banks listed at Amman stock exchange and the Palestinian banks listed at Nablus stock exchange, in regard to the commitment level of accounting information systems to the reliability principles of electronic systems. The study variables represented in the readiness, security, operations safety, privacy, and confidentiality and connect them with the dependent variable represented in the banking performance indicators. The study measured the reliability level of AIS in commercial banks of Jordan and Palestine by determining its commitment level with the reliability or trust principles of electronic systems through the questionnaire that was addressed to the employees of information systems departments, where the questionnaire included questions about the availability level of each reliability principle of AIS.

The most important results of the study conclude that Jordanian and Palestinian banks work environment, as well as the technological infrastructure provide the requirements of those reliability principles at statistically good and acceptable ratios, the existence of an effect for providing the AIS in Jordan and Palestinian banks to the reliability principles at the financial performance matrix, and also the existence of moral significance effect for providing the AIS in Jordanian and Palestinian banks to the system reliability principles at the operational performance matrix. But in regard to the impact of AIS in Palestinian and Jordanian banks to the reliability principles at the stock performance matrix, the study found statistically significant impact for providing system reliability principles in the ordinary share earnings, and study did not find any difference between the Jordanian and Palestinian banks, except in the principle related to the company confidential information of AIS. The most important recommendations of the study states that internal auditor should be invited to perform the controlling task on the reliability of information systems, invite the external auditor to confirm the trust in accounting systems, and the need from agencies that regulate banks operations in Jordan and Palestine to adopt the reliability of information systems, and require it as a condition to practice the profession.

Alrabei (2014) study aimed to evaluate the impact of AIS at Jordanian Islamic banks. The most important results conclude that banks rely on accounting systems by connecting all the banking services of each department separately and linking between all departments at the same time, Jordanian Islamic banks depend on AIS to satisfy the clients through the implementation of electronic clients banking at a quick manner and minimum effort. In order to determine the research objectives, a questionnaire was designed and distributed on the financial managers, accountants, interior auditors, and heads of accounting departments at the Islamic banks of Jordan. A total of (42) questionnaires were distributed, and (35) of those were retrieved with a percentage of $(83.33 \%)$, which consider acceptable for study purposes, and were analyzed using SPSS and other statistical methods. Results showed that AIS are most common in the Jordanian Islamic banks and it help by providing the appropriate information about the available substances, at the right time. In addition, some conclusions and suggestions for further research were discussed.

Jawabreh and Alrabei (2012) study aimed to identify the reality of AIS in four and five-star hotels, in terms of planning, controlling, and decision making. A questionnaire was designed and distributed on the various hotel accountants in order to collect data related to the study topic, and used the descriptive analytical method to statistically analyze and test these data. The results indicate that hotels in Jodhpur did not use the AIS methods in planning, controlling, and decision-making processes. Results also indicate that all grouped items have a mean of (1.77 \& 0.00), (1.85\& 0.00), and (1.98 \& 0.00), respectively, which means that study hypotheses are rejected due to nonexistence of relationship between accounting information system and planning, controlling, and decision-making in the four and five-stars Jodhpur hotels. Study recommends an increase in the rehabilitation and training of staffs, and the development and implementation of efficient accounting information system methods at the Jodhpur hotels. The study of Ismail (2011) aimed to identify the characteristics of information systems and its impact on determining the strategic competition selection at the upper and middle managements of commercial banks operating in the Gaza Strip. Study sample consist of the (10) commercial banks operating in the Gaza Strip, where (67) questionnaires were distributed, and used the descriptive analytical method in order to statistically analyze and test data collected in this study. The results showed an awareness at the banks about the importance of security and confidentiality of clients and to maintain their deposited money through adopting clear policies and procedures, and verified that information systems had large and important role in achieving the competitive advantage for banks operating in the Gaza Strip, and information systems also provided valuable knowledge to the bank in order to improve the quality of service and develop new services to give banks the superiority over competitors. The study recommended upgrading and increasing the efficiency of information systems and information systems components (hardware, software, telecommunications, databases, individuals, procedures) and configuring it according to the technological advances.

The study of Ahmed (2006) aimed to identify the effectiveness level of using AIS in the planning processes, translating goals, and formulating policies of the company, in addition to the availability level of supervisory criteria and indicators needed for identifying the problem and making the necessary decisions effectively, at the Palestinian shareholding companies. To achieve the study objectives and answer its questions, the researcher depends on the previous studies and literature to collect data related to the study topic, and through it the secondary data were obtained which formed the theoretical framework of the study, while the practical framework depends on preparing a questionnaire that was designed for this purpose, and researcher 
made the required analyses and tested the study hypotheses. Study arrived to a set of important conclusions and recommendations related to using AIS at the Palestinian shareholding companies, it found some signs of reduction in putting manuals for accounts to determine the operation confirmation and process methods, along with lack of necessary attention to develop the skills of workers in the accounting area, which require the need from management to care about providing the necessary features and potentials to operate an efficient and effective accounting system, results showed a low effectiveness level of using AIS in the planning processes, translating goals, and formulating policies of the company, in addition to lack of supervisory criteria and indicators needed to identify the problem and make the necessary decisions effectively, which call for the need to pay attention to provide the required information for planning, controlling, and making the good decisions. The results also showed a reduction in conducting the necessary analysis of surrounding environmental elements which affect the quality of decisions made, and this requires the need to pay attention to the factors surrounding the company before setting up and developing AIS, to ensure the efficiency and effectiveness of these systems. Additionally, the study results indicate limited interest by companies to deal with the regulatory considerations related to the design and development of AIS, which require management to pay attention to these considerations, and in particular the participation of individuals in the preparation and development of AIS, as well as the importance to define the organizational structure of the company and make use of modern information technology.

\section{Study Methodology, Statistical Analysis \& Hypothesis Testing}

Data were collected from the secondary sources by reviewing reference books, scientific research, and accounting literature which are related to the study topic, and specialize in accounting information systems and their reliability in enhancing and promoting the planning requirements, while data were collected from the primary sources by preparing a questionnaire to identify and achieve the main goals of the study. The study population consists of all (13) commercial banks, while the study sample consists of employees in the financial sections and departments, users of accounting information system, and accounting personnel. Researcher distributed (145) questionnaires on each bank and were given to the department heads of accounting and financial managers, retrieved (122), and exclude only (4) as it were invalid for analysis, where (2) questionnaires were incomplete and two others were answered strongly agree for all responses, and (118) questionnaires remained valid for analysis with $(81 \%)$.

Study Population \& Sample: study consists of all staff at the accounting and financial departments, and the internal audit unit of the (13) Jordanian commercial banks, (145) questionnaires were distributed on each bank of the study sample, researcher retrieved (122) questionnaires and after reviewing the recovered questionnaires, it turn out that (4) of those questionnaires are extremely unfit and invalid for statistical analysis, and (118) questionnaires remain valid for analysis.

Study Sample Characteristics: Table 1 shows the demographic characteristics of individuals who respond to the questionnaires, which consist of age, job title, qualifications, specialization, years of experience, and professional certificates, where study sample members were distributed according to its variables as follows:

Table 1

Distribution of study sample members according to the personal variables

\begin{tabular}{|c|c|c|c|c|c|c|c|}
\hline Variable & Level & Frequency & $\%$ & Variable & Level & Frequency & $\%$ \\
\hline \multirow{5}{*}{ Age } & 29 or less & 2 & 1.7 & \multirow{4}{*}{ Specialization } & Accounting & 101 & 85.6 \\
\hline & $30-39$ & 60 & 50.8 & & Business Administration & 4 & 3.4 \\
\hline & $40-50$ & 53 & 44.9 & & Economics & 1 & 0.8 \\
\hline & 51 or more & 3 & 2.5 & & Finance \& Banking & 12 & 10.2 \\
\hline & Total & 118 & 100.0 & & Total & 118 & 100.0 \\
\hline \multirow{5}{*}{ Job Title } & General Manager & 3 & 2.5 & \multirow{4}{*}{$\begin{array}{c}\text { Years of } \\
\text { Experience }\end{array}$} & 5 Yrs or less & 19 & 16.1 \\
\hline & Financial Manager & 28 & 23.7 & & $6-10$ & 30 & 25.4 \\
\hline & Department Head & 36 & 30.5 & & $11-15$ & 32 & 27.1 \\
\hline & Others & 51 & 43.2 & & 16 or more & 37 & 31.4 \\
\hline & Total & 118 & 100.0 & & Total & 118 & 100.0 \\
\hline \multirow{5}{*}{ Qualifications } & Diploma & 6 & 5.1 & \multirow{4}{*}{$\begin{array}{l}\text { Professional } \\
\text { certificates }\end{array}$} & JCPA & 7 & 5.9 \\
\hline & $\mathrm{BA}$ & 89 & 75.4 & & CPA & 7 & 5.9 \\
\hline & MA & 17 & 14.4 & & ACPA & 5 & 4.2 \\
\hline & $\mathrm{PhD}$ & 6 & 5.1 & & Others & 11 & 9.3 \\
\hline & Total & 118 & 100.0 & & NA & 88 & 74.6 \\
\hline
\end{tabular}

Table 1 shows that study sample members are eligible to respond to the questionnaire items and rely on it in their answers, which enhance and strengthen the results of this study.

Study Tool Sincerity \& Stability Test:

Tool Sincerity: the sincerity of tool content used in the study was verified by introducing it on a group of faculty members with the expertise, efficiency, and corporate managements, who amount to (9) arbitrators to express their opinions in every area of the study, drafting of items, and the connection between each item and the aspect that correspond to it, and according to their remarks and suggestions some questions were modified, other were deleted, and new questions were added. Therefore, 
study tool (questionnaire) in its final form become to contain (41) items, which are spread over (6) areas or aspects, see attachment (1).

Tool Stability: it means constancy of results, its reliability, and its ability to make predictions, or it could mean the compatibility or consistency level of questionnaire results if it were implemented more than once in similar circumstances. To calculate the stability of the study tool, it was divided into six areas or aspects to measure the stability of each area separately and for the tool as a whole, and the internal consistency test (Cronbach Alpha) was used to test the study sample responses that were obtained from the study tool. It is also possible to interpret Alpha as the internal consistency coefficient between the answers or responses, its high value refer to a high degree of reliability or stability, where the statistically acceptable value for this scale or measurement is $(60 \%)$ or more (Sekaran \& Bougie, 2017), and according to other studies the statistically acceptable value is $(70 \%)$ or more, and it is clear from the results of data analysis in Table 2 that results of study items stability came to a high degree.

Table 2

Internal stability coefficients (Cronbach Alpha) for each area of the study tool and the tool as a whole

\begin{tabular}{lcc}
\multicolumn{1}{c}{ Aspect } & Number of Items & Cronbach Alpha \\
\hline The Protection of AIS from unauthorized intrusions & 7 & 77.4 \\
Criteria of making AIS ready for activation & 6 & 80.5 \\
The integration and safety criteria of AIS operations & 7 & 78.1 \\
Ensure the privacy of customers who deal with the bank & 5 & 78.1 \\
Ensure the protection of confidential information & 6 & 79.2 \\
Planning process requirements & 10 & 85.1 \\
\hline Tool as a Whole & 55 & 89.0 \\
\hline
\end{tabular}

It shows from Table 2 that all Cronbach Alpha Coefficient values were high and also the study items stability as a whole was high at a percentage of (89.0), which indicate that study tool hold a high stability and credibility level.

Normal distribution: Table 3 shows the result of normal distribution data test, where (Skewness \& Kurtosis) test was used and the results were as follows:

Table 3

Normal distribution data test (Skewness \& Kurtosis)

\begin{tabular}{lcc}
\multicolumn{1}{c}{ Aspect } & Skewness & Kurtosis \\
\hline The Protection of AIS from unauthorized intrusions & -0.354 & 1.566 \\
Criteria of making AIS ready for activation & -0.477 & 1.221 \\
The integration and safety criteria of AIS operations & -0.606 & 0.871 \\
Ensure the privacy of customers who deal with the bank & -0.665 & 1.284 \\
Ensure the protection of confidential information & -0.332 & 0.908 \\
Planning process requirements & 0.616 & -0.178 \\
\hline
\end{tabular}

Table 3 shows that test value of Skewness lies between $(1.96 \pm)$ and Kurtosis test value lies between $(2.85 \pm)$, therefore data are subject to normal distribution (Hair et al., 2010). It shows from Table 4, the test interference (correlation) between the independent variables (VIF value) and Tolerance, and depends on (VIF) test to confirm there are no problems of multiple linear relationships (Multi Correlation), because it considers as one of the problems that face the statistical estimation of Regression Coefficient, Table (4) shows the results of (VIF) test:

Table 4

Test interference (correlation) between the independent variables (VIF value) and Tolerance

\begin{tabular}{lcc}
\multicolumn{1}{c}{ Aspect } & VIP & Tolerance \\
\hline The Protection of AIS from unauthorized intrusions & 1.63 & 0.61 \\
Criteria of making AIS ready for activation & 1.12 & 0.89 \\
The integration and safety criteria of AIS operations & 1.11 & 0.91 \\
Ensure the privacy of customers who deal with the bank & 1.23 & 0.82 \\
Ensure the protection of confidential information & 1.43 & 0.70 \\
\hline
\end{tabular}

Table 4 above shows no problem of multi-correlations between the independent variables, as it's less than 5, therefore accept the level of variation in each independent variables.

Study Results Discussion: Table 5 shows that $R^{2}$ value amount to (0.357), which means that independent variables explain $(35.7 \%)$ from the variation in the dependent variable, and also the value of $F=12.423$ at a statistically significance level of $(0.00)$. 
Table 5

Independent variables \& variation of dependent variable

\begin{tabular}{|c|c|c|c|}
\hline Independent variables & $\beta$-value & $T$-value & Sig \\
\hline Constant & 0.197 & 0.389 & 0.698 \\
\hline The protection of AIS from unauthorized intrusions & 0.213 & 2.205 & 0.029 \\
\hline Criteria of making AIS ready for activation & 0.186 & 2.314 & 0.022 \\
\hline The integration and safety criteria of AIS operations & 0.166 & 2.088 & 0.039 \\
\hline Ensure the privacy of customers who deal with the bank & 0.202 & 2.410 & 0.018 \\
\hline Ensure the protection of confidential information & 0.196 & 2.168 & 0.032 \\
\hline $\begin{array}{c}F \text {-value } \\
\text { Adj. } R^{2} \\
\text { Durbin-Watson }\end{array}$ & $\begin{array}{c}12.423 \\
0.328 \\
1.732\end{array}$ & $\begin{array}{l}\text { Sig } F \\
\quad R^{2} \\
\quad \text { Number of observation }\end{array}$ & $\begin{array}{c}0.000 \\
0.357 \\
118\end{array}$ \\
\hline
\end{tabular}

Results of the first hypothesis: there is no statistically significant impact for the protection of AIS from unauthorized intrusions on enhancing the requirements of planning process at Jordanian Commercial Banks, multiple regression result showed a positive relationship between the protection of AIS from unauthorized intrusions and enhancing planning requirements at Jordanian Commercial Banks, where the result indicates that increasing independent variable by an average of one unit would increase the dependent variable by (0.213), with a $t$-value of (2.205) and statistical significance of (0.029), therefore the null hypothesis would be rejected and we accept the alternative hypothesis.

Results of the second hypothesis: There is no statistically significant impact of AIS readiness activation standards on enhancing the requirements of planning process at Jordanian Commercial Banks. Table 5 shows that $B$-value $=0.186$, where the result indicates that increasing AIS readiness by an average of one unit would increase enhancing the requirements of planning process at Jordanian Commercial Banks by (18.6\%), with a $t$-value of (2.314) and statistical significance of $(0.022)$, therefore the null hypothesis would be rejected and we accept the alternative hypothesis.

Results of the Third hypothesis: There is no statistically significant impact of AIS integration and safety standards on enhancing the requirements of planning process at Jordanian Commercial Banks. Table (5) shows showed a positive relationship between AIS integration and safety standards and enhancing the planning requirements of Jordanian Commercial Banks, where the result indicates that increasing independent variable by an average of one unit would increase the dependent variable by $(16.6 \%)$, with a $t$-value of (2.088) and statistical significance of $(0.018)$, therefore the null hypothesis would be rejected and we accept the alternative hypothesis.

Results of the Forth hypothesis: There is no statistically significant impact of AIS customers' privacy assurance on enhancing the requirements of planning process at Jordanian Commercial Banks. As shown in table (5) the multiple linear regression result indicate that $B$-value $=(0.202)$ and the $t$-value $=(2.41)$ at statistically significant value of $(0.032)$, which indicate a statistically significant positive relationship, and mean that increasing AIS customers' privacy assurance by an average of one unit would increase enhancing the requirements of planning process at Jordanian Commercial Banks by (0.202), therefore the null hypothesis would be rejected and we accept the alternative hypothesis.

Results of the Fifth hypothesis: There is no statistically significant impact of AIS confidential information protection on enhancing the requirements of planning process at Jordanian Commercial Banks. Table (5) shows a statistically significant positive relationship between AIS confidential information protection and enhancing the planning requirements of Jordanian Commercial Banks, where the result indicates that $B$-value $=(0.196)$ and the $t$-value $=(2.168)$ at statistically significant value of (0.032), and mean that increasing the independent variable by an average of one unit would increase the dependent variable by $(19.6 \%)$, therefore the null hypothesis would be rejected and we accept the alternative hypothesis.

\section{Study Results \& Recommendations}

\subsection{Study results}

After the statistical analysis and the hypotheses testing, the study has arrived to the following results:

- The results of analysis show positive relationship for the protection of AIS from unauthorized intrusions on enhancing the planning requirements of Jordanian Commercial Banks, where the result of this study agreed with the following studies (Abu-Mahdi, 2017; Mushtaha et al., 2011; Ismail, 2011).

- The results of analysis show positive relationship for AIS readiness activation standards on enhancing the requirements of planning process at Jordanian Commercial Banks, where the result of this study agreed with the following studies (Abu-Mahdi, 2017; Mushtaha et al., 2011; Ismail, 2011).

- The results of analysis show positive relationship for AIS integration and safety standards on enhancing the planning requirements of Jordanian Commercial Banks, where the result of this study agreed with the following studies (AbuMahdi, 2017; Mushtaha et al., 2011; Ismail, 2011).

- The results of analysis showed positive relationship for AIS customers' privacy assurance on enhancing the requirements of planning process at Jordanian Commercial Banks, where the result of this study agreed with the following studies (Abu-Mahdi, 2017; Mushtaha et al., 2011; Ismail, 2011). 
- The results of analysis showed positive relationship for AIS confidential information protection on enhancing the requirements of planning process at Jordanian Commercial Banks, where the result of this study agreed with the following studies (Abu-Mahdi, 2017; Mushtaha et al., 2011; Ismail, 2011).

\subsection{Study Recommendations}

Researcher made the following recommendations:

- The need to update and develop AIS continuously in order for their outputs to be compatible with the requirements of Jordanian banks management and organizational levels to make the various decisions, taking into account to give all decisions the information it need.

- The need of Jordanian banks management to give more attention to the development of work procedures to be compatible with the reliability of AIS.

- The need of Jordanian banks management to conduct continuous training courses for all workers on the developed and sophisticated systems, in order to keep up with the developments in the business.

- The need of researchers, academic staffs, and concerned people, in the future to conduct more researches in the area of current study.

\section{References}

Abu-Hasheish, K.A. (2005). Management accounting for planning decisions rationalization. $1^{\text {st }}$ ed., Dar Wael for publishing $\&$ distribution, Amman, Jordan

Abu-Mahdi, S. (2017), The impact of electronic accounting information systems reliability on banking performance indicators. unpublished master thesis, Islamic University, Gaza, Palestine

Ahmed, B.M. (2006). The role of accounting information systems in rationalizing the administrative decisions at the Palestinian business firms, an empirical study on limited liability stock companies in the Gaza Strip. Unpublished master thesis, Islamic University, Gaza

Al-Dalahmeh, S.M. (2008). Accounting information systems \& information technology. $1^{\text {st }}$ ed., Al-Waraq for publishing \& distribution, Amman, Jordan.

Al-Mbaidin, T.H. (2014). The Effectiveness of Accounting Information System in Jordanian Banks: From the Management Perspective. International Bulletin of Business Administration, 14, 135-147.

Alrabei, A. M. (2014). The impact of accounting information system on the Islamic banks of Jordan: An empirical study. European Scientific Journal, 10(4).

Al-Rumhi, N.M., \& Al-Zeibah, Z.A.-H. (2011). Accounting information systems, $1^{\text {st }}$ edition, Dar Massira for publishing \& distribution, Amman, Jordan.

Edmond Gel, E. T. (2010). Effectiveness level of accounting information systems in private Iraqi commercial banks, from the standpoint of management. unpublished master thesis, Middle East University, Amman, Jordan.

Hair, Black, Babin \& Anderson (2010). Multivariate Data Analysis. $7^{\text {th }}$ ed, Upper saddle River, new Jersey, Person Education International.

Harem, H. (2009). Principles of modern management, management processes, and Organization functions, $2^{\text {nd }}$ edition, Dar Hamid for publishing \& distribution, Amman, Jordan.

Ismail, E. A. (2011). Characteristics of information systems and its impact on identifying the strategic competition choice in upper and middle managements, an empirical study on the commercial banks operating in the Gaza Strip. unpublished master thesis, Islamic University, Gaza.

Jawabreh, O. \& Alrabei, A. M. (2012). The impact of accounting information system in planning, controlling and decisionmaking processes in Jodhpur Hotels. Asian Journal of Finance \& Accounting, 4(1).

Kahaleh, G. J., \& Hanan, R. (2011). Management Accounting: accounting responsibility and performance evaluation approach. $1^{\text {st }}$ edition, International Scientific House \& Culture House for publishing \& distribution, Amman, Jordan

Kanakriyah, R. (2017). The impact of accounting information systems on the banks success: Evidence from Jordan. Research Journal of Finance and Accounting, 8(17).

Phuong, N. T.T. (2017). The roles of information systems in linking management accounting and financial accounting: Empirical evidence from Vietnam. Accounting and Finance Research, 6, 4.

Sekaran, U., \& Bougie, R. (2016). Research methods for business: A skill building approach. John Wiley \& Sons.

Tawfiq, A.-R. (2010). Financial planning and control. $2^{\text {nd }}$ ed., Future publishing and distribution House, Amman, Jordan.

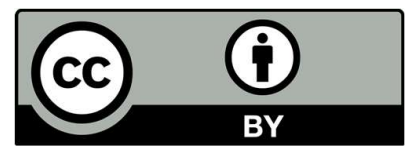

(C) 2020 by the authors; licensee Growing Science, Canada. This is an open access article distributed under the terms and conditions of the Creative Commons Attribution (CC-BY) license (http://creativecommons.org/licenses/by/4.0/). 